\title{
A Group of Descending Glutamatergic Neurons Activated by Stress in Corticolimbic Regions Project to the Nucleus Accumbens
}

\author{
Jin-Young Park ${ }^{1}$, So Young Park ${ }^{1}$, Hyejin Kwon ${ }^{1}$, Yumi Song ${ }^{1}$, Boin Yun ${ }^{1}$, Yubin Lee ${ }^{1}$, \\ Yeryung Cho ${ }^{1}$, Ahran Joo ${ }^{1}$ and Pyung-Lim Han ${ }^{1,2 *}$ \\ ${ }^{1}$ Department of Brain and Cognitive Sciences, Ewha Womans University, Seoul 03760, \\ ${ }^{2}$ Department of Chemistry and Nano Science, Ewha Womans University, Seoul 03760, Korea
}

\begin{abstract}
The nucleus accumbens (NAc) is the major component of the ventral striatum that regulates stress-induced depression. The NAc receives dopaminergic inputs from the ventral tegmental area (VTA), and the role of VTA-NAc neurons in stress response has been recently characterized. The NAc also receives glutamatergic inputs from various forebrain structures including the prelimbic cortex (PL), basolateral amygdala (BLA), and ventral hippocampus (vHIP), whereas the role of those glutamatergic afferents in stress response remains underscored. In the present study, we investigated the extent to which descending glutamatergic neurons activated by stress in the PL, BLA, and vHIP project to the NAc. To specifically label the input neurons into the NAc, fluorescent-tagged cholera toxin subunit B (CTB), which can be used as a retrograde neuronal tracer, was injected into the NAc. After two weeks, the mice were placed under restraint for $1 \mathrm{~h}$. Subsequent histological analyses indicated that CTB-positive cells were detected in 170 680 cells $/ \mathrm{mm}^{2}$ in the PL, BLA, and vHIP, and those CTB-positive cells were mostly glutamatergic. In the PL, BLA, and vHIP regions analyzed, stress-induced c-Fos expression was found in 20 100 cells $/ \mathrm{mm}^{2}$. Among the CTB-positive cells, $2.6 \%$ in the PL, 4.2\% in the BLA, and $1.1 \%$ in the vHIP were co-labeled by c-Fos, whereas among c-Fos-positive cells, $7.7 \%$ in the PL, $19.8 \%$ in the BLA, and $8.5 \%$ in the vHIP were co-labeled with CTB. These results suggest that the NAc receives a significant but differing proportion of glutamatergic inputs from the PL, BLA, and vHIP in stress response.
\end{abstract}

Key words: Stress, c-Fos, Retrograde tracer, Nucleus accumbens

\section{INTRODUCTION}

The nucleus accumbens (NAc) is the key component of the ventral striatum that regulates reward, drug addiction, depression, and

Received July 2, 2018, Revised October 2, 2018, Accepted October 5, 2018

* To whom correspondence should be addressed. TEL: 82-2-3277-4130, FAX: 82-2-3277-3419 e-mail:plhan@ewha.ac.kr stress $[1,2]$. The NAc receives dopaminergic inputs from the ventral tegmental area (VTA) $[3,4]$ and glutamatergic afferents from corticolimbic structures including the prelimbic cortex (PL), basolateral amygdala (BLA), and ventral hippocampus (vHIP) $[5,6]$, which are important in regulating stress and emotions $[1,7]$. NAc neurons project to the ventral pallidum (VP), lateral habenula, and medial dorsal nucleus and ventral lateral nucleus of the thalamus $[8,9]$.

The functional importance of the NAc and VTA dopaminergic inputs to the NAc in stress-induced depressive behaviors have
Copyright ( $\odot$ Experimental Neurobiology 2018. www.enjournal.org
This is an Open Access article distributed under the terms of the Creative Commons Attribution Non-Commercial License (http://creativecommons.org/licenses/by-nc/4.0) which permits unrestricted non-commercial use, distribution, and reproduction in any medium, provided the original work is properly cited. 
been characterized [1, 2, 10-12]. Chronic social defeat stress increased the firing rate of VTA-to-NAc dopaminergic neurons [13, 14]. Optogenetic phasic stimulation of VTA-to-NAc neurons, but not VTA-to-medial prefrontal cortex (mPFC) neurons, facilitated depressive-like behaviors. Conversely, optogenetically inhibiting the VTA-to-NAc circuit was anti-depressive, whereas inhibiting the VTA-to-mPFC projection produced depressive effects [15]. Stimulating mPFC-to-NAc neurons facilitated anti-depressive behaviors [16], whereas activating hippocampal or thalamic inputs [16], and ventral hippocampal inputs [17] to the NAc promoted depressive-like behaviors. Stimulating BLA-to-NAc glutamatergic neurons promoted cue-evoked sucrose intake, which required the activation of an intra-NAc dopamine D1 receptor signaling [18]. Glutamatergic synaptic strength in the NAc shell medium spiny neurons (MSNs) was increased after stress [19]. Overall, these studies suggest that the NAc receives not only dopaminergic VTA neurons, but also glutamatergic inputs from corticolimbic regions. However, the role of those glutamatergic neurons in regulating stress and depressive behaviors has only recently received attention $[16,17,20-22]$.

Stimulation dependent c-Fos expression has been used to map brain regions that are activated under specific conditions [23-28]. For example, stress- or exercise-dependent c-Fos induction has been used to identify and characterize brain regions that are activated by stress [11,29-31] or exercise [32-35]. Recently, functional labeling of specific neurons with a c-Fos promoter combined with sophisticated optogenetics or pharmacogenetics methods makes it possible to pinpoint the functional networks that mediate contextdependent behavioral changes in cognition and emotion [36-38].

In the present study, we investigated the extent to which descending glutamatergic neurons activated by stress in the mPFC, vHIP, and BLA innervate the NAc by using a combined method of staining neurons with activity-dependent c-Fos expression and a fluorescent retrograde marker, Alexa-conjugated cholera toxin subunit $\mathrm{B}$ (CTB). We identified a group of glutamatergic neurons in the $\mathrm{mPFC}, \mathrm{vHIP}$, and BLA that projected into the NAc and were activated by acute stress.

\section{MATERIALS AND METHODS}

\section{Animals}

Seven-week-old male C57BL/6J mice were purchased from a local supplier (Daehan BioLink Inc., Chungbuk, Korea). Upon arriving, they were grouped according to an experimental design and housed in pairs in regular plastic cages in a temperature- $\left(23^{\circ} \mathrm{C}\right)$ and humidity-controlled (50 60\%) room with a 12/12-hour light/ dark cycle (light on at 7 A.M.). Mice were allowed access to food and water ad libitum in home cage, and were acclimated to the laboratory environment for 1 week before stereotaxic surgery. All procedures followed the animal care guidelines of Ewha Womans University School of Medicine (IACUC 16-018).

\section{Stereotaxic injection}

Stereotaxic surgery was performed as described previously [39, 40] with minor modifications. In brief, mice were anesthetized by intraperitoneal (i.p.) injection of 3.5:1 mixture of ketamine (50 $\mathrm{mg} / \mathrm{ml})$ and xylazine hydrochloride $(23.3 \mathrm{mg} / \mathrm{ml})$ at $2 \mu \mathrm{l} / \mathrm{g}$ body weight. After $5 \mathrm{~min}$, the mouse was staged on the surgical apparatus (Stoelting Co., Wood Dale, IL, USA). Cholera toxin subunit B (CTB) conjugated with Alexa Fluor ${ }^{\mathrm{TM}} 488$ (\#C34755; Molecular Probes, USA) was delivered at $0.5 \mu \mathrm{l} / \mathrm{min}$ in $0.4 \mu \mathrm{l}$ volume into each of both NAc regions (AP, $+1.4 \mathrm{~mm}$; ML, $\pm 1.3 \mathrm{~mm}$; DV, -5.0 $\mathrm{mm}$ from bregma) with a $30 \mathrm{G}$ needle (Top Medical, Korea), Tygon ${ }^{\circledR}$ microbore tubing (\#AAD04091; Saint-Gobain, USA), and a Hamilton microsyringe (\#CAL80030; Hamilton, USA). CTB solution $(0.1 \%, \mathrm{w} / \mathrm{v})$ was prepared by dissolving CTB in sterile PBS ( $\mathrm{pH}$ 7.28). After the injection finished, the needle was left in place for $3 \mathrm{~min}$ and removed with three intermediate steps over $3 \mathrm{~min}$ to minimize backflow. After the skin was sewn, mice were kept on a warm pad $\left(30^{\circ} \mathrm{C}\right)$ until they awoke. To ensure retrograde transport, CTB-injected mice were kept for two weeks in their home cage before starting the experimental schedule.

\section{Restraint stress}

Mice were restrained as described previously [39-41]. Mice were individually placed in a 50-ml conical tube (\#50050; SPL Life Science, Korea) that had many ventilation holes and were pushed toward the conical end. Tail side was plugged with a $3-\mathrm{cm}$ piece from the middle of a $15-\mathrm{ml}$ tube (\#50015; SPL Life Science). The tube was closed with a cap that had a hole for the mouse's tail. Tubes were placed in home cage for $1 \mathrm{~h}$. Mice were restrained beginning at 10 A.M.

\section{Immunohistochemistry}

Immunohistochemistry was carried out as described previously $[39,40]$. Mice were anesthetized with $2.5 \%(\mathrm{w} / \mathrm{v})$ avertin (\#T48402; Aldrich, USA) at $20 \mu \mathrm{l} / \mathrm{g}$ body weight, perfused with saline, and fixed with 4\% (w/v) paraformaldehyde solution (\#P6148; SigmaAldrich, USA). The fixed brain was cut into $40-\mu \mathrm{m}$-thick coronal sections using a vibratome (\#VT1000S; Leica, German), and sections were stored in cryo-buffer (containing $30 \%$ glycerol) at $-20^{\circ} \mathrm{C}$.

Brain sections at the levels of the PL $(\mathrm{AP},+1.9 \mathrm{~mm})$, NAc (AP, $+1.3 \mathrm{~mm}$ ), BLA (AP, $-1.3 \mathrm{~mm}$ ), and vHIP (AP, $-3.1 \mathrm{~mm})$ were used 
A

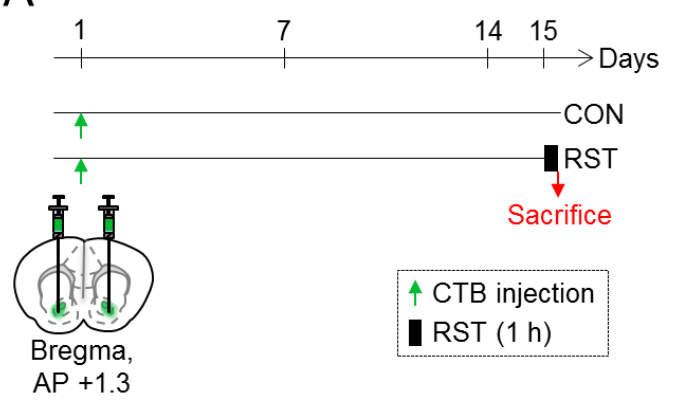

B

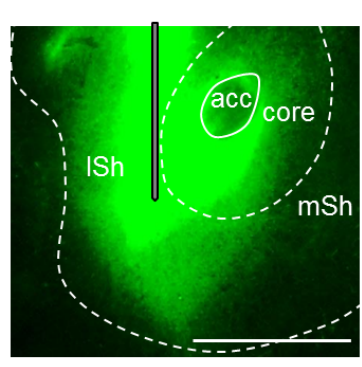

C 다이 toxin

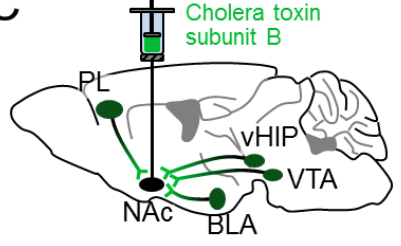

$\mathrm{D}$ Endocytosis

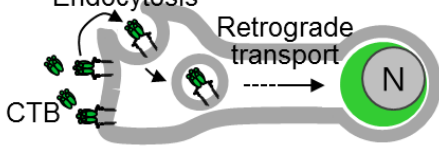

E

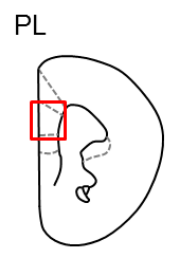

Bregma,

AP $+1.9 \mathrm{~mm}$
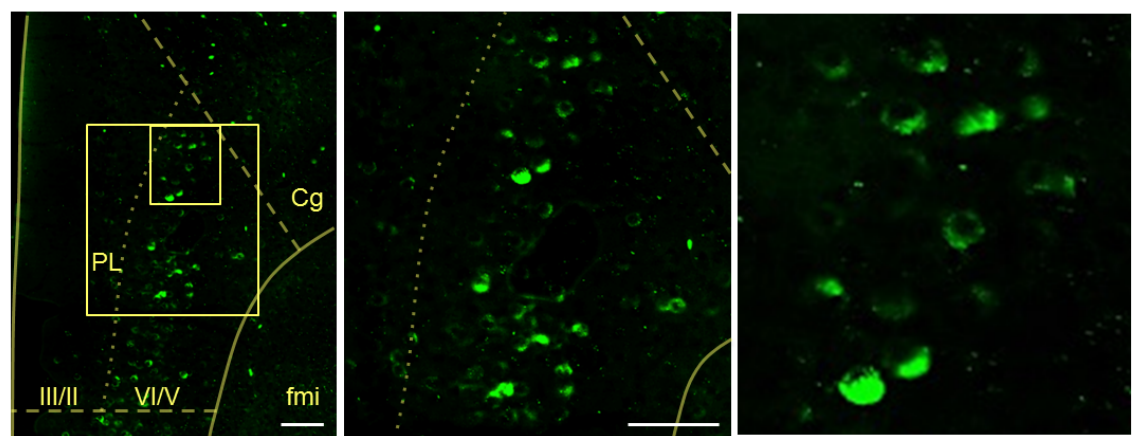

F
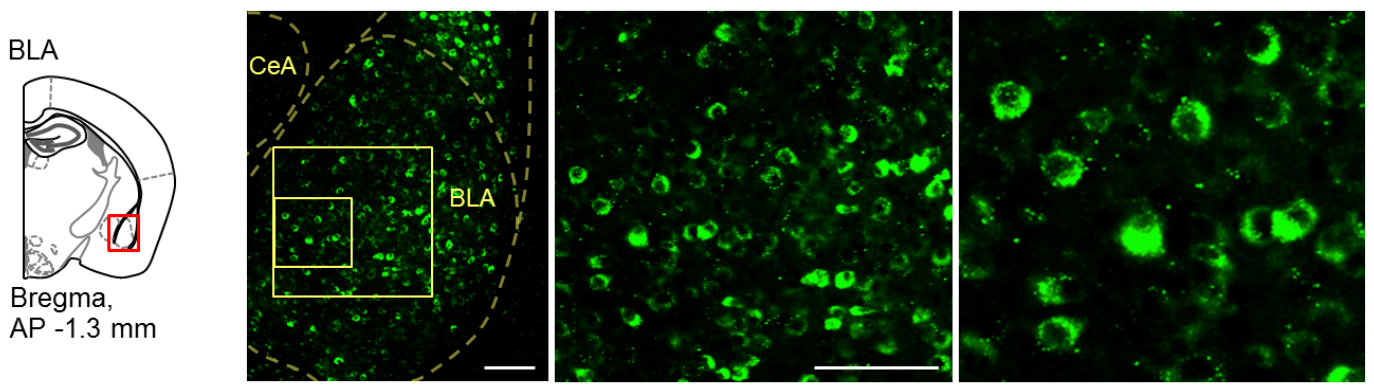

G
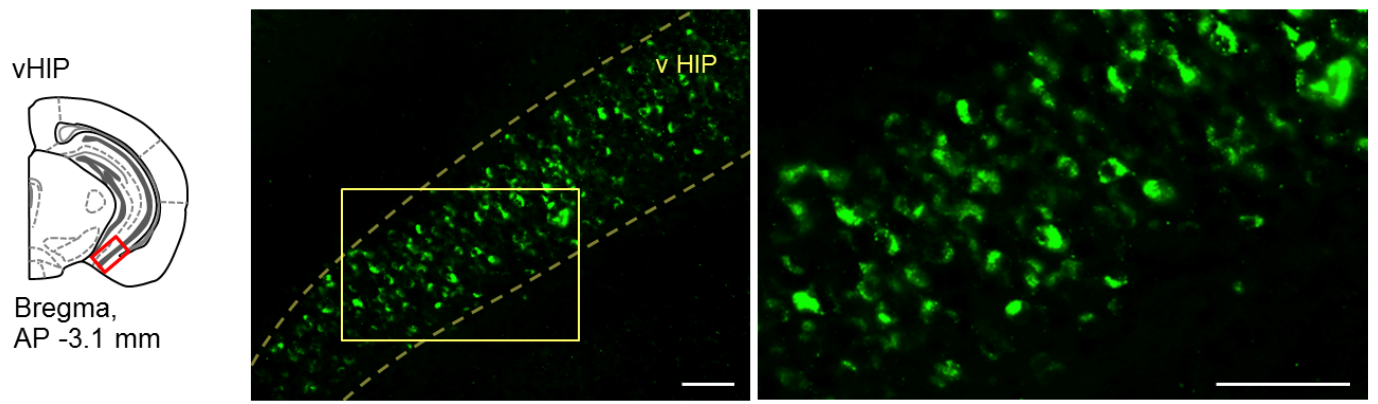

Fig. 1. Retrograde labeling of neurons projecting into the NAc. (A) Experimental design and time schedule for CTB injection (green arrows) into the NAc. After 14 days of the surgery, 1-h restraint was treated. Red arrow, time point for tissue preparation. CON, CTB-injected control mice; RST, CTBinjected and stress treated mice. (B, C) A fluorescence image (B) of Alexa-conjugated CTB (cholera toxin subunit B) expression in the lateral core and shell of the NAc 14 days after the surgery and a schematic diagram (C) of CTB injection (left panel). Projections from the prelimbic cortex (PL), ventral hippocampus (vHIP), ventral tegmental area (VTA), and basolateral amygdala (BLA) are indicated. acc, anterior commissures; core, NAc core; ISh, lateral shell of the NAc; mSH, medial shell of the NAc. Scale bar, $500 \mu \mathrm{m}$. (D) Schematic diagram illustrating endocytosis of CTB at the synaptic terminal and retrograde transport of fluorescent CTB along the axon and its translocation into the cell body region (adapted from [63, 64]). (E G) CTB-positive cells in the PL (E), BLA (F), and vHIP (G). Schematic diagrams illustrating the coronal sections at the level of the PL (E), BLA (F), and vHIP (G). High magnification of the areas marked with a rectangle. Cg, cingulate cortex; fmi, anterior forceps minor of the corpus callosum; VI/V, cortical layers VI/V; II/III, cortical layers II/III; BLA, basolateral amygdala; CeA, central amygdala. Scale bars; $50 \mu \mathrm{m}$ in the PL and BLA, and vHIP. 
for immunohistochemical analysis. The sections were washed with PBS three times, blocked with 5\% BSA in PBST (PBS containing $0.1 \%$ Triton $\mathrm{X}-100)$ for $1 \mathrm{~h}$ at $4^{\circ} \mathrm{C}$, and incubated with monoclonal anti-glutamate antibody derived from the GLU-4 hybridoma clone (1:500; \#G-9282; Sigma, USA) or c-Fos antibody (1:1000; \#sc-52; Santa Cruz Biotechnology, USA) in 5\% BSA blocking solution overnight. After washing, the sections were incubated with secondary antibody, DyLight ${ }^{\circledR}$-549 horse anti-rabbit IgG (1:200: \#DI-1094; Vector Laboratories, USA), for $2 \mathrm{~h}$ at room temperature. After washing, stained sections were mounted on a gelatin-coated glass slide with mounting solution (\#S3023; Dako, Japan) and a cover slide.

Stained sections were examined with a fluorescence microscope (\#BX51; Olympus, Japan) and filters specific for Alexa Fluor ${ }^{\mathrm{TM}} 488$ (\#39002; Chroma Technology, USA) and Dylight ${ }^{\circledR} 594$ (\#39010;
Chroma Technology, USA). Image analysis was performed with MetaMorph $^{\circledR}$ software (Molecular Devices, USA).

\section{Statistical analysis}

Two-sample comparisons were performed with Student's ttest. PRISM software 6 (GraphPad Software, USA) was used for statistical analyses. All data are presented as the mean \pm SEM, and statistical differences were accepted at the $5 \%$ level.

\section{RESULTS}

To specifically label a group of neurons in the limbic system that projected into the NAc, a fluorescent retrograde neuronal tracer, Alexa-conjugated cholera toxin subunit B (CTB) [42-44], was stereotaxically injected into the NAc lateral core and shell on both
A

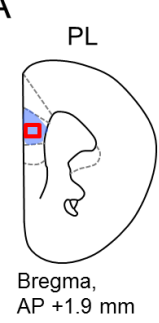

D

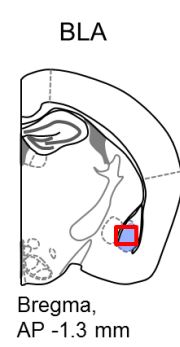

G

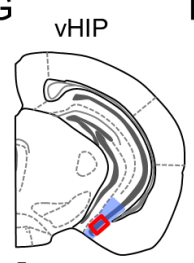

Bregma,

AP $-3.1 \mathrm{~mm}$
B

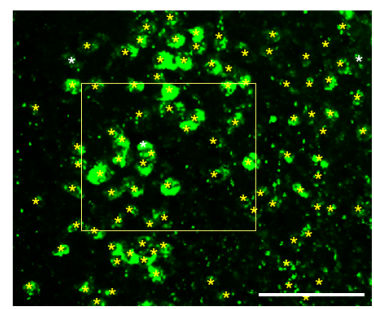

E

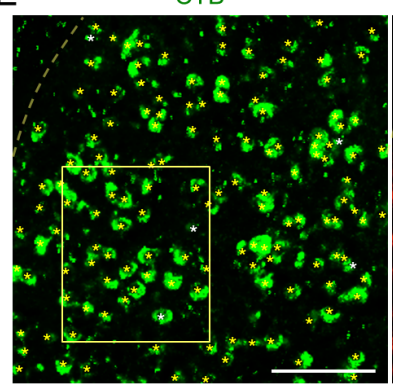

$\mathrm{H}$

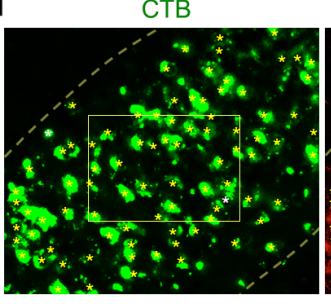

GLU-4

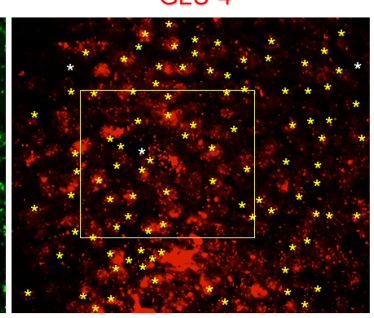

GLU-4

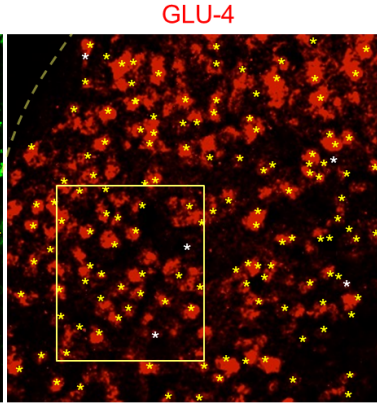

GLU-4

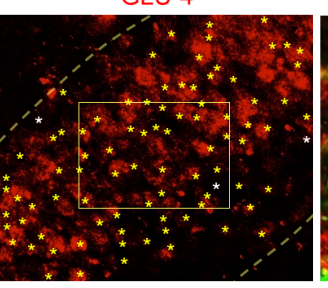

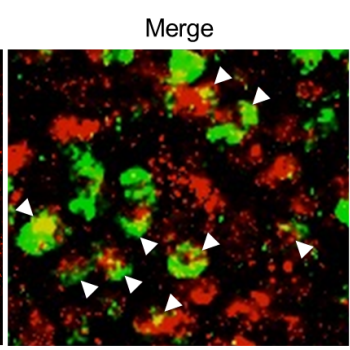

C

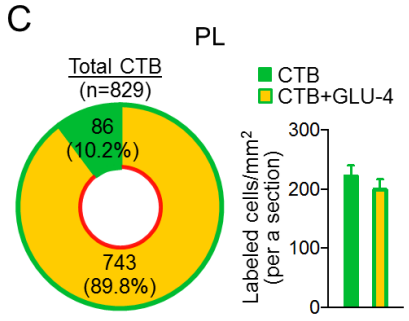

F
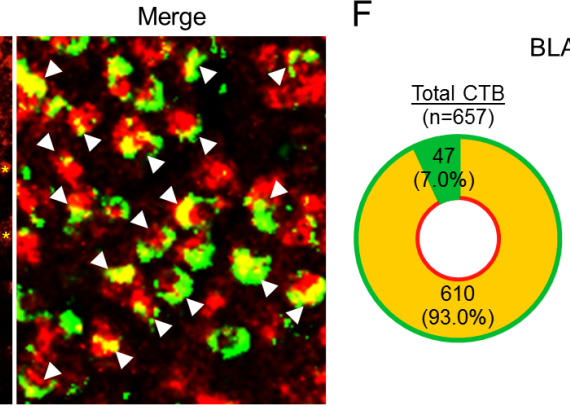

BLA

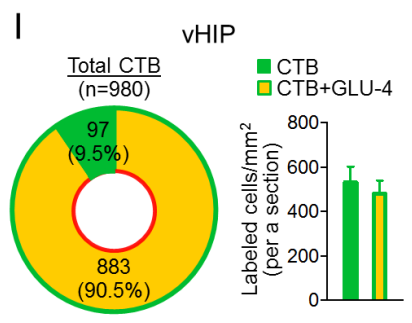

Fig. 2. Most of CTB-positive cells in PL, BLA, and vHIP regions were stained by GLU-4, a glutamatergic neuron marker. (A I) Schematic diagrams illustrating the coronal section of the PL (A), BLA (D), and vHIP (G), and the areas (filled blue area) analyzed for cells labeled by fluorescent-CTB (green) and anti-glutamate antibody (GLU-4, red). Fluorescence images showing cells labeled with CTB (green), or GLU-4 (red), and high magnification of an overlay (boxed areas, merged) in the PL (B), BLA (E), and vHIP (H). Quantification of CTB labeled cells, GLU-4 labeled cells, and CTB plus GLU4 double-labeled cells in the PL (C), BLA (F), and vHIP (I). Venn diagrams showing the summed numbers of cells stained with CTB only (green) or CTB+GLU-4 (yellow) counted in the sections of PL (C), BLA (F), and vHIP (I) regions. Bar graphs showing the normalized mean number in mm ${ }^{2}$ of cells stained with CTB only (green) and double-labeled with CTB+GLU-4 (yellow) in the PL (C), BLA (F), and vHIP (I). n=4 animals for each region. *indicates cells stained with CTB or GLU-4. Arrow heads indicate cells stained with CTB and GLU-4. Scale bars; $50 \mu \mathrm{m}$ in the PL and BLA, and $100 \mu \mathrm{m}$ in the vHIP. All data are mean \pm SEM. Student's t-test. 
sides (Fig. 1A, B). After surgery, mice were placed in their home cages for 2 weeks, allowing that the fluorescent tagged CTB could be transported to the cell body of neurons in the PL, BLA, and vHIP (Fig. 1C). Then, CTB-injected mice were then restrained for $1 \mathrm{~h}$ (Fig. 1A). Immediately after restraint, mice were sacrificed, and brains were histologically examined. CTB-injected unrestrained mice were used as a control. We previously demonstrated that restraint for $1 \mathrm{~h}$ induced significant $\mathrm{c}$-Fos levels in most forebrain regions without saturation [11]. We confirmed that fluorescentlabeled CTB was detected in various brain regions including the PL, BLA, and vHIP (Fig. 1D G).

Next, we examined whether CTB-labeled neurons in the PL, $\mathrm{BLA}$, and vHIP are glutamatergic using monoclonal anti-gluta- mate antibody (GLU-4 for short), which has been used for labeling glutamatergic neurons $[45,46]$. In the PL region examined (AP, $1.98 \pm 0 \mathrm{~mm}), 89.8 \%$ of CTB-labeled neurons cells (743/829) were stained by GLU-4 antibody, a specific marker for labeling glutamatergic neurons, whereas $10.2 \%$ (86/829) were not labeled by GLU4 (Fig. $2 \mathrm{~A} \sim \mathrm{C}$ ). In the BLA region examined (AP, $1.31 \pm 0.03 \mathrm{~mm}$ ), 93.0\% of CTB-labeled neurons (610/657) were positive to GLU4, whereas $7.0 \%$ (47/657) were not labeled by GLU-4 antibody (Fig. 2D F). In the vHIP region examined (AP, $-3.19 \pm 0.03 \mathrm{~mm}$ ), 90.5\% of CTB-labeled neurons (883/980) were positive to GLU-4, whereas 9.5\% (97/980) were not stained by GLU-4 (Fig. 2G I).

Further analyses indicated that in the PL region of control mice, CTB-positive cells were counted in $175 \pm 54$ cells $/ \mathrm{mm}^{2}$, and c-Fos-
A

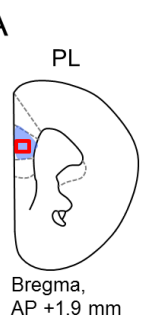

B

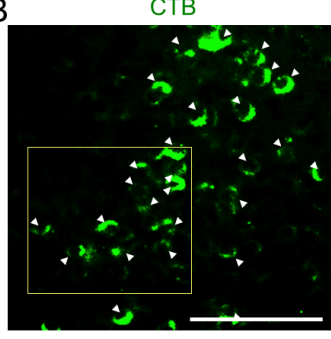

E

D

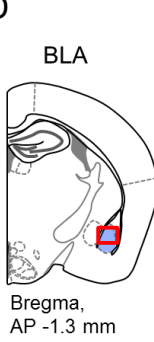

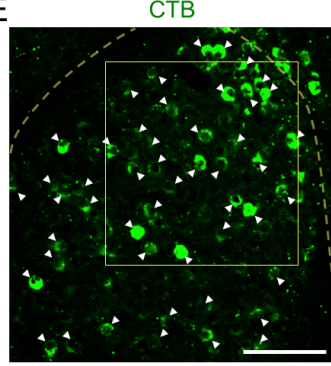

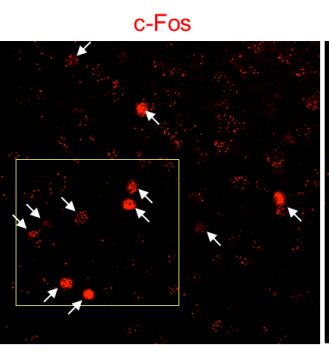

c-Fos

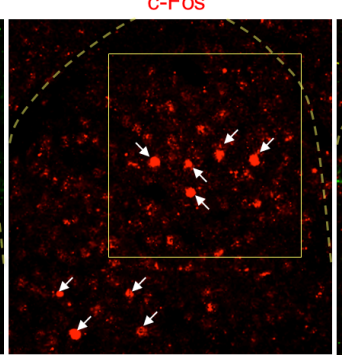

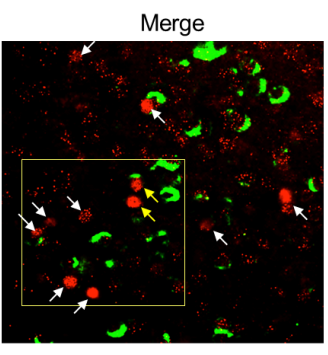

Merge

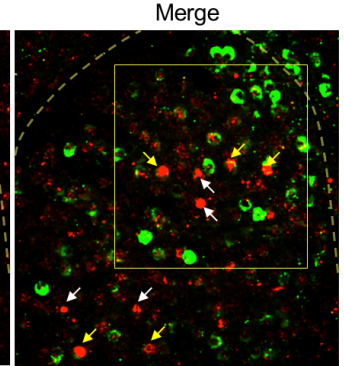

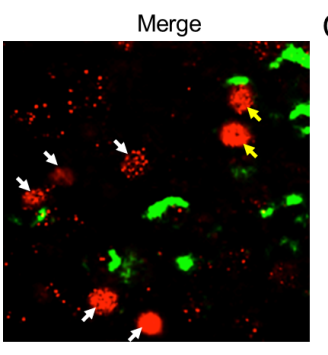
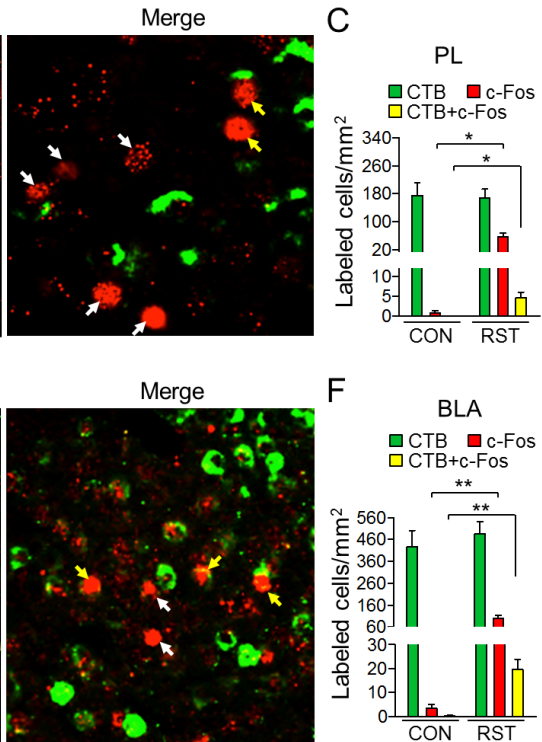

$\mathrm{F}$

BLA $\square$ CTB $\square \mathrm{C}-\mathrm{Fos}$

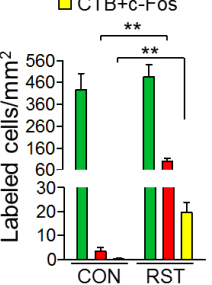

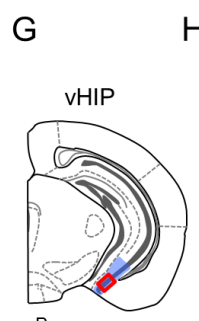

Bregma, AP $-3.1 \mathrm{~mm}$
$\mathrm{H}$

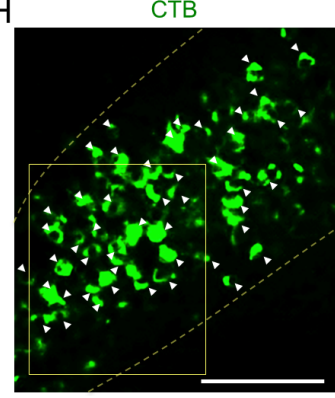

c-Fos

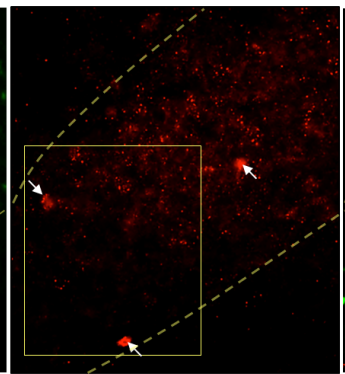

Merge

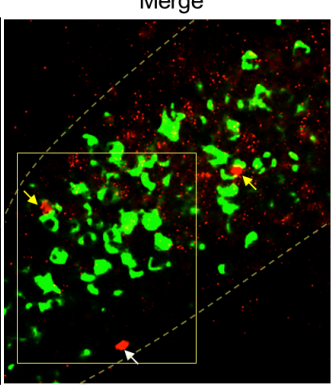

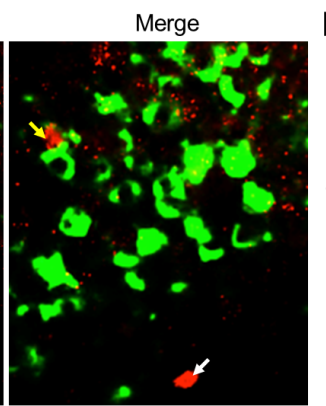

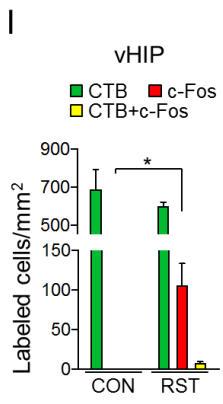

Fig. 3. Analyses of cells stained by the stimulation-dependent neural activity marker c-Fos and the retrograde tracer CTB in PL, BLA, and vHIP neurons. (A I) Schematic diagrams illustrating the coronal section of the PL (A), BLA (D), and vHIP (G), the areas (filled blue area) analyzed for cells stained by c-Fos and/or fluorescent CTB, and high magnification (boxed areas). Fluorescence images showing cells labeled with CTB (green) or c-Fos (red), and high magnification of an overlay of CTB and c-Fos labeled cells (boxed area) in the PL (B), BLA (E), and vHIP (H). Arrow heads indicate CTBpositive cells and arrows indicate c-Fos-positive cells. Scale bars: Scale bars; $50 \mu \mathrm{m}$ in the PL and BLA, and $100 \mu \mathrm{m}$ in the vHIP. The examined sections of the PL were at the level of $1.95 \pm 0.01 \mathrm{~mm}$ (AP) from the bregma, those of the BLA were at $-1.39 \pm 0.03 \mathrm{~mm}$, and those of the vHIP were at $-3.22 \pm 0.04 \mathrm{~mm}$. The numbers of animals examined were $n=3 \sim 4$ animals for the PL, $n=4 \sim 5$ animals for the BLA, and $n=3$ animals each for the vHIP. Quantification of CTB labeled cells, c-Fos labeled cells, and CTB and c-Fos double-labeled cells in the PL (C), BLA (F), and vHIP (I) of control (CON) and restrained (RST) mice. All data are mean \pm SEM. ${ }^{*} \mathrm{p}<0.05,{ }^{* *} \mathrm{p}<0.01$ (Student's t-test). 
positive cells were detected in $1 \pm 0$ cells $/ \mathrm{mm}^{2}$ (Fig. 3A C; CON). In contrast, in the PL region of mice treated with restraint, $\mathrm{CTB}$ positive cells were found in $167 \pm 36$ cells $/ \mathrm{mm}^{2}$, and c-Fos-positive cells were counted in $58 \pm 15$ cells $/ \mathrm{mm}^{2}$ (Fig. 3A C; RST). Double labeling analysis indicated that among the CTB-positive cells in the PL, 2.7\% (23/837) were co-labeled by stress-induced c-Fos, whereas of the stress-induced c-Fos-positive cells, 8.0\% (23/289) were co-labeled by CTB (Fig. 4).

In the BLA region of control mice, $\mathrm{CTB}$-positive cells were detected in $428 \pm 91$ cells $/ \mathrm{mm}^{2}$, and c-Fos-positive cells were found in $3 \pm 1$ cells $/ \mathrm{mm}^{2}$ (Fig. 3D F; CON). Whereas in the BLA region of mice treated with restraint, CTB-labeled cells were counted in $488 \pm 74$ cells $/ \mathrm{mm}^{2}$, and c-Fos-positive cells were found in $98 \pm 20$ cells $/ \mathrm{mm}^{2}$ (Fig. 3D F). Double labeling analysis indicated that among the CTB-positive cells in the BLA, 4.0\% (59/1464) were colabeled by stress-induced c-Fos, whereas of the stress-induced cFos-positive cells, 20.1\% (59/294) were co-labeled by CTB (Fig. 4).

In the vHIP region of control mice, $\mathrm{CTB}$-positive cells were found in $684 \pm 105$ cells $/ \mathrm{mm}^{2}$, and c-Fos-positive cells were detected in $0 \pm 0$ cells $/ \mathrm{mm}^{2}$ (Fig. $3 \mathrm{G} \sim \mathrm{I}$; CON). In contrast, in the vHIP region of mice treated with restraint, CTB-labeled cells were counted in $608 \pm 32$ cells $/ \mathrm{mm}^{2}$, and c-Fos-positive cells were detected in $105 \pm 21$ cells $/ \mathrm{mm}^{2}$ (Fig. 3G I). Double labeling analysis indicated that among the CTB-positive cells in the vHIP, 1.1\% (8/726) were co-labeled by stress-induced c-Fos, whereas of the stress-induced
c-Fos-positive cells in the vHIP, 6.3\% (8/128) were co-labeled by CTB (Fig. 4).

Overall, these results suggest that a group of glutamatergic neurons in the PL, BLA, and vHIP were projecting to the NAc, among which $2.7 \%$ (23/837) in the PL, 4.0\% (59/1464) in the BLA and $1.1 \%(8 / 726)$ in the vHIP were activated by stress. Among the cFos-positive cells counted, $8.0 \%$ (23/289) of neurons in the PL, $20.1 \%(59 / 294)$ of neurons in the BLA, and 6.3\% (8/128) of neurons in the vHIP projected to the NAc (Fig. 4).

\section{DISCUSSION}

The NAc is the core of the ventral striatum that integrates various excitatory inputs from the medial prefrontal cortex (mPFC), vHIP, and amygdala (Amy), and it regulates emotionally motivated behaviors and action-related behaviors [2, 7]. The NAc receives not only dopaminergic inputs, but also glutamatergic inputs from forebrain structures $[5,6]$. Our results also indicate that the NAc region receives significant levels of glutamatergic inputs from the PL, BLA, and vHIP. Approximately $167 \pm 36$ cells $/ \mathrm{mm}^{2}$ in the $\mathrm{PL}, 488 \pm 74$ cells $/ \mathrm{mm}^{2}$ in the BLA, and $608 \pm 32$ cells $/ \mathrm{mm}^{2}$ in the vHIP were labeled by fluorescent CTB. However, among the CTBpositive cells, only $2.7 \%$ of cells in the PL, $4.0 \%$ of cells in the BLA, and $1.1 \%$ of cells in the vHIP were co-labeled with c-Fos. These results suggesting that most NAc-projecting cells in the PL, BLA, and

A

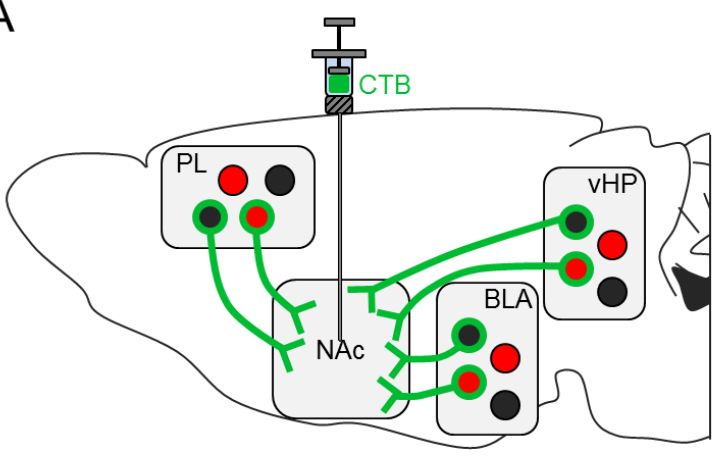

CTB positive cell c-Fos positive cell

B

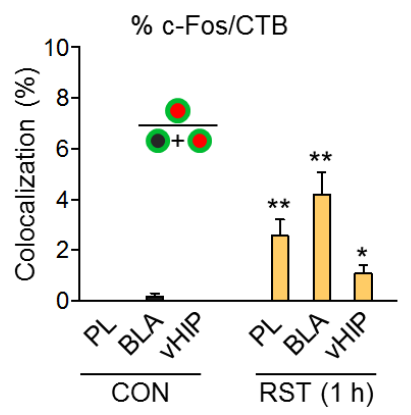

C

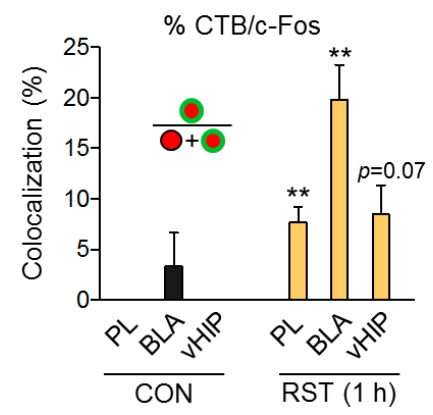

Fig. 4. Proportion of neurons stained by c-Fos or CTB. (A) A schematic diagram illustrating PL, BLA, and vHIP neurons projecting to the NAc. Cells labeled by CTB (green line and circle) or expressing cFos protein (filled red circle). Fluorescent CTB was injected into the NAc. (B) Percentage of CTB-labeled cells that are c-Fos-positive in the PL, BLA, and vHIP in control $(\mathrm{CON})$ and mice treated with 1 -h restraint (RST). (C) Percentage of c-Fos-positive cells that were also CTB-labeled in the PL, vHIP, and BLA. All data are mean \pm SEM ( $n=3 \sim 5$ animals for each region). ${ }^{*} \mathrm{p}<0.05,{ }^{* *} \mathrm{p}<0.01$ (Student's t-test). 
vHIP appear to be silent or not directly related to stress response, whereas there are a group of glutamatergic neurons projecting to the NAc in the PL, BLA, and vHIP that are activated by stress.

On the other hand, concerning the c-Fos-positive cells, $8.0 \%$ of cells in the PL, $6.3 \%$ of cells in the vHIP, and $20.1 \%$ of cells in the BLA were co-labeled by CTB. Thus, among the stress-activated cells, a relatively high portion of cells in the PL, vHIP, and BLA are projecting to the NAc. In particular, 20.1\% of c-Fos-positive neurons in the BLA projected into the NAc, raising the possibility that there might be a possible role of BLA-to-NAc neurons in regulating stress responses. Optogenetic stimulation of glutamatergic BLA-to-NAc neurons suppressed reward seeking behaviors, which required intra-NAc dopamine D1 receptor signaling [18]. Following repeated restraint, the vHIP was inappropriately activated, which indirectly reduced the neural activity of the BLAto-NAc pathway [47]. Optogenetic stimulation of vHIP-to-NAc projections promoted depressive-like behaviors [48], whereas optogenetically stimulating mPFC-to-NAc neurons facilitated antidepressive behaviors [16]. Collectively, these results suggest that the NAc receives, and thereby is regulated by, various descending glutamatergic neurons in the PL, vHIP, and BLA. Of the descending glutamatergic neurons projecting to the NAc, a relatively small group of neurons are activated in stress responses, but their relative percentages among the stress-activated cells were $8.0 \%$ in the PL, 6.3\% in the vHIP, and $20.1 \%$ in the BLA, and thus they are not low.

Mice subjected to chronic social defeat stress had an increased firing rate of VTA-to-NAc dopaminergic neurons, and this change was responsible for depressive behavior [13, 14]. Consistently, optogenetic phasic stimulation of VTA-to-NAc neurons, but not VTA-to-mPFC neurons, facilitated depressive behaviors [15]. Mice treated with chronic, unpredictable, mild stress (CUMS) or chronic restraint stress (CRST) exhibited depressive behaviors [41, 49-52], but mice treated with CUMS or CRST had reduced excitability of VTA-to-NAc neurons [53-55]. These studies suggest that the activities of VTA dopaminergic neurons and the NAc are regulated differently in different stress models, even though they all result in depressive behavior. Concerning this complexity, it will be worthy to test whether descending glutamatergic inputs to the NAc and their downstream neural circuits differ depending on the stress model for the expression of depressive behaviors.

Our results indicate that a group of glutamatergic neurons activated by stress in the PL, vHIP, and BLA project into the NAc. However, this result needs to be interpreted in line with the following points. CTB-labeled NAc-projecting neurons in the PL, BLA, and vHIP are likely excitatory glutamatergic neurons $[5,56]$. In fact, most of CTB-labeled neurons were positive to the staining with GLU-4 antibody (Fig. 2). However, 10.2\% of the CTB-labeled neurons in the PL, 7.0\% in the BLA, and 9.5\% in the vHIP were not stained by GLU-4 antibody (Fig. 2). It is possible that those GLU4-negative cells are long-range GABA neurons [57, 58]. However, considering that many neurons in the brain previously thought to release glutamate as neurotransmitter also release the inhibitory neurotransmitter GABA [59], more sophisticated tools, such as a genetic marker for GABAergic neurons, might be useful to precisely define the identity of those cells. The CTB-viral vector injection labeled the lateral core and shell on both sides of the NAc (Fig. 1), but it could not label all NAc neurons nor label NAc neurons at the same efficacy. Projections to more medial parts of the NAc were not effectively labeled in the present study. Nonetheless, our results present the relative proportion of PL, vHIP, and BLA nondopaminergic neurons that projected to the injected sites of the NAc and how they were activated by stress.

Our results might be used for the following type of experiments. A transgenic strategy carrying an optogenetic tool [60] or a viral vector-mediated Gq-DREADD (designer receptor exclusively activated by the designer drug; hM3Dq) system [61], when combined with activity-dependent labeling of neurons with specific tools, such as cre-recombinase or transcription factors [62], might be used to investigate whether the cell groups activated by stress in the PL, vHIP, or BLA have a modulatory role in stress-dependent behavioral changes or depressive behaviors.

\section{ACKNOWLEDGEMENTS}

This research was supported by a grant (2018R1A2B2001535) from the Ministry of Science, ICT and Future Planning, Republic of Korea.

\section{REFERENCES}

1. Russo SJ, Nestler EJ (2013) The brain reward circuitry in mood disorders. Nat Rev Neurosci 14:609-625.

2. Floresco SB (2015) The nucleus accumbens: an interface between cognition, emotion, and action. Annu Rev Psychol 66:25-52.

3. Beier KT, Steinberg EE, DeLoach KE, Xie S, Miyamichi K, Schwarz L, Gao XJ, Kremer EJ, Malenka RC, Luo L (2015) Circuit architecture of VTA dopamine neurons revealed by systematic input-output mapping. Cell 162:622-634.

4. Aransay A, Rodríguez-López C, García-Amado M, Clascá F, Prensa L (2015) Long-range projection neurons of the mouse ventral tegmental area: a single-cell axon tracing analysis. Front Neuroanat 9:59.

5. Britt JP, Benaliouad F, McDevitt RA, Stuber GD, Wise RA, 
Bonci A (2012) Synaptic and behavioral profile of multiple glutamatergic inputs to the nucleus accumbens. Neuron 76:790-803.

6. Floresco SB, Todd CL, Grace AA (2001) Glutamatergic afferents from the hippocampus to the nucleus accumbens regulate activity of ventral tegmental area dopamine neurons. J Neurosci 21:4915-4922.

7. Francis TC, Lobo MK (2017) Emerging role for nucleus accumbens medium spiny neuron subtypes in depression. Biol Psychiatry 81:645-653.

8. Marín O, Smeets WJ, González A (1998) Evolution of the basal ganglia in tetrapods: a new perspective based on recent studies in amphibians. Trends Neurosci 21:487-494.

9. Zahm DS (2000) An integrative neuroanatomical perspective on some subcortical substrates of adaptive responding with emphasis on the nucleus accumbens. Neurosci Biobehav Rev 24:85-105

10. Krishnan V, Graham A, Mazei-Robison MS, Lagace DC, Kim KS, Birnbaum S, Eisch AJ, Han PL, Storm DR, Zachariou V, Nestler EJ (2008) Calcium-sensitive adenylyl cyclases in depression and anxiety: behavioral and biochemical consequences of isoform targeting. Biol Psychiatry 64:336-343.

11. Kim KS, Han PL (2009) Mice lacking adenylyl cyclase-5 cope badly with repeated restraint stress. J Neurosci Res 87:29832993.

12. Liljeholm M, O'Doherty JP (2012) Contributions of the striatum to learning, motivation, and performance: an associative account. Trends Cogn Sci 16:467-475.

13. Krishnan V, Han MH, Graham DL, Berton O, Renthal W, Russo SJ, Laplant Q, Graham A, Lutter M, Lagace DC, Ghose S, Reister R, Tannous P, Green TA, Neve RL, Chakravarty S, Kumar A, Eisch AJ, Self DW, Lee FS, Tamminga CA, Cooper DC, Gershenfeld HK, Nestler EJ (2007) Molecular adaptations underlying susceptibility and resistance to social defeat in brain reward regions. Cell 131:391-404.

14. Cao JL, Covington HE 3rd, Friedman AK, Wilkinson MB, Walsh JJ, Cooper DC, Nestler EJ, Han MH (2010) Mesolimbic dopamine neurons in the brain reward circuit mediate susceptibility to social defeat and antidepressant action. J Neurosci 30:16453-16458.

15. Chaudhury D, Walsh JJ, Friedman AK, Juarez B, Ku SM, Koo JW, Ferguson D, Tsai HC, Pomeranz L, Christoffel DJ, Nectow AR, Ekstrand M, Domingos A, Mazei-Robison MS, Mouzon E, Lobo MK, Neve RL, Friedman JM, Russo SJ, Deisseroth K, Nestler EJ, Han MH (2013) Rapid regulation of depressionrelated behaviours by control of midbrain dopamine neurons. Nature 493:532-536.
16. Bagot RC, Parise EM, Peña CJ, Zhang HX, Maze I, Chaudhury D, Persaud B, Cachope R, Bolaños-Guzmán CA, Cheer JF, Deisseroth K, Han MH, Nestler EJ (2015) Ventral hippocampal afferents to the nucleus accumbens regulate susceptibility to depression. Nat Commun 6:7062.

17. Christoffel DJ, Golden SA, Walsh JJ, Guise KG, Heshmati M, Friedman AK, Dey A, Smith M, Rebusi N, Pfau M, Ables JL, Aleyasin H, Khibnik LA, Hodes GE, Ben-Dor GA, Deisseroth K, Shapiro ML, Malenka RC, Ibanez-Tallon I, Han MH, Russo SJ (2015) Excitatory transmission at thalamo-striatal synapses mediates susceptibility to social stress. Nat Neurosci 18:962964.

18. Stuber GD, Sparta DR, Stamatakis AM, van Leeuwen WA, Hardjoprajitno JE, Cho S, Tye KM, Kempadoo KA, Zhang F, Deisseroth K, Bonci A (2011) Excitatory transmission from the amygdala to nucleus accumbens facilitates reward seeking. Nature 475:377-380.

19. Campioni MR, Xu M, McGehee DS (2009) Stress-induced changes in nucleus accumbens glutamate synaptic plasticity. J Neurophysiol 101:3192-3198.

20. Rada P, Moreno SA, Tucci S, Gonzalez LE, Harrison T, Chau DT, Hoebel BG, Hernandez L (2003) Glutamate release in the nucleus accumbens is involved in behavioral depression during the PORSOLT swim test. Neuroscience 119:557-565.

21. Hultman R, Mague SD, Li Q, Katz BM, Michel N, Lin L, Wang J, David LK, Blount C, Chandy R, Carlson D, Ulrich K, Carin L, Dunson D, Kumar S, Deisseroth K, Moore SD, Dzirasa K (2016) Dysregulation of prefrontal cortex-mediated slowevolving limbic dynamics drives stress-induced emotional pathology. Neuron 91:439-452.

22. Knowland D, Lim BK. (2018) Circuit-based frameworks of depressive behaviors: the role of reward circuitry and beyond. Pharmacol Biochem Behav (in press).

23. Bullitt E (1990) Expression of c-fos-like protein as a marker for neuronal activity following noxious stimulation in the rat. J Comp Neurol 296:517-530.

24. Cullinan WE, Herman JP, Battaglia DF, Akil H, Watson SJ (1995) Pattern and time course of immediate early gene expression in rat brain following acute stress. Neuroscience 64:477-505.

25. Herrera DG, Robertson HA (1996) Activation of c-fos in the brain. Prog Neurobiol 50:83-107.

26. Perrotti L, Hadeishi Y, Ulery PG, Barrot M, Monteggia L, Duman RS, Nestler EJ (2004) Induction of deltaFosB in rewardrelated brain structures after chronic stress. J Neurosci 24:10594-10602.

27. Schmidt B, Marrone DF, Markus EJ (2012) Disambiguating 
the similar: the dentate gyrus and pattern separation. Behav Brain Res 226:56-65.

28. Cruz FC, Koya E, Guez-Barber DH, Bossert JM, Lupica CR, Shaham Y, Hope BT (2013) New technologies for examining the role of neuronal ensembles in drug addiction and fear. Nat Rev Neurosci 14:743-754.

29. Zhang J, Wu Z, Zhou L, Li H, Teng H, Dai W, Wang Y, Sun ZS (2011) Deficiency of antinociception and excessive grooming induced by acute immobilization stress in Perl mutant mice. PLoS One 6:e16212.

30. Ma Y, Matsuwaki T, Yamanouchi K, Nishihara M (2014) Differential roles of cyclooxygenase-2-related signaling in regulating hypothalamic neuronal activity under various acute stresses. J Vet Med Sci 76:219-227.

31. Maras PM, Molet J, Chen Y, Rice C, Ji SG, Solodkin A, Baram TZ (2014) Preferential loss of dorsal-hippocampus synapses underlies memory impairments provoked by short, multimodal stress. Mol Psychiatry 19:745.

32. Oladehin A, Waters RS (2001) Location and distribution of Fos protein expression in rat hippocampus following acute moderate aerobic exercise. Exp Brain Res 137:26-35.

33. Seo JH, Kim TW, Kim CJ, Sung YH, Lee SJ (2013) Treadmill exercise during pregnancy ameliorates post traumatic stress disorder induced anxiety like responses in maternal rats. Mol Med Rep 7:389-395.

34. Hong H, Kim CJ, Kim JD, Seo JH (2014) $\beta$-glucan reduces exercise-induced stress through downregulation of c-Fos and c-Jun expression in the brains of exhausted rats. Mol Med Rep 9:1660-1666.

35. Kim TK, Han PL (2016) Chronic stress and moderate physical exercise prompt widespread common activation and limited differential activation in specific brain regions. Neurochem Int 99:252-261.

36. Liu X, Ramirez S, Pang PT, Puryear CB, Govindarajan A, Deisseroth K, Tonegawa S (2012) Optogenetic stimulation of a hippocampal engram activates fear memory recall. Nature 484:381-385.

37. Kawashima T, Okuno H, Bito H (2014) A new era for functional labeling of neurons: activity-dependent promoters have come of age. Front Neural Circuits 8:37.

38. Minatohara K, Akiyoshi M, Okuno H (2016) Role of immediate-early genes in synaptic plasticity and neuronal ensembles underlying the memory trace. Front Mol Neurosci 8:78.

39. Choi J, Kim JE, Kim TK, Park JY, Lee JE, Kim H, Lee EH, Han PL (2015) TRH and TRH receptor system in the basolateral amygdala mediate stress-induced depression-like behaviors. Neuropharmacology 97:346-356.
40. Kim TK, Lee JE, Kim JE, Park JY, Choi J, Kim H, Lee EH, Han PL (2016) G9a-mediated regulation of OXT and AVP expression in the basolateral amygdala mediates stress-induced lasting behavioral depression and its reversal by exercise. Mol Neurobiol 53:2843-2856.

41. Park JY, Kim TK, Choi J, Lee JE, Kim H, Lee EH, Han PL (2014) Implementation of a two-dimensional behavior matrix to distinguish individuals with differential depression states in a rodent model of depression. Exp Neurobiol 23:215-223.

42. Hirakawa M, McCabe JT, Kawata M (1992) Time-related changes in the labeling pattern of motor and sensory neurons innervating the gastrocnemius muscle, as revealed by the retrograde transport of the cholera toxin B subunit. Cell Tissue Res 267:419-427.

43. Conte WL, Kamishina H, Reep RL (2009) Multiple neuroanatomical tract-tracing using fluorescent Alexa Fluor conjugates of cholera toxin subunit B in rats. Nat Protoc 4:1157-1166.

44. Lerner TN, Ye L, Deisseroth K (2016) Communication in neural circuits: tools, opportunities, and challenges. Cell 164:1136-1150.

45. Madl JE, Larson AA, Beitz AJ (1986) Monoclonal antibody specific for carbodiimide-fixed glutamate: immunocytochemical localization in the rat CNS. J Histochem Cytochem 34:317-326.

46. Zhu LQ, Wang SH, Liu D, Yin YY, Tian Q, Wang XC, Wang Q, Chen JG, Wang JZ (2007) Activation of glycogen synthase kinase-3 inhibits long-term potentiation with synapse-associated impairments. J Neurosci 27:12211-12220.

47. Gill KM, Grace AA (2013) Differential effects of acute and repeated stress on hippocampus and amygdala inputs to the nucleus accumbens shell. Int J Neuropsychopharmacol 16:2013-2025.

48. Christoffel DJ, Golden SA, Walsh JJ, Guise KG, Heshmati M, Friedman AK, Dey A, Smith M, Rebusi N, Pfau M, Ables JL, Aleyasin H, Khibnik LA, Hodes GE, Ben-Dor GA, Deisseroth K, Shapiro ML, Malenka RC, Ibanez-Tallon I, Han MH, Russo SJ (2015) Excitatory transmission at thalamo-striatal synapses mediates susceptibility to social stress. Nat Neurosci 18:962964.

49. Willner P, Towell A, Sampson D, Sophokleous S, Muscat R (1987) Reduction of sucrose preference by chronic unpredictable mild stress, and its restoration by a tricyclic antidepressant. Psychopharmacology (Berl) 93:358-364.

50. Willner P, Muscat R, Papp M (1992) Chronic mild stressinduced anhedonia: a realistic animal model of depression. Neurosci Biobehav Rev 16:525-534.

51. Willner P (2005) Chronic mild stress (CMS) revisited: con- 
sistency and behavioural-neurobiological concordance in the effects of CMS. Neuropsychobiology 52:90-110.

52. Kim KS, Lee KW, Lee KW, Im JY, Yoo JY, Kim SW, Lee JK, Nestler EJ, Han PL (2006) Adenylyl cyclase type 5 (AC5) is an essential mediator of morphine action. Proc Natl Acad Sci U S A 103:3908-3913.

53. Cabib S, Puglisi-Allegra S (1996) Stress, depression and the mesolimbic dopamine system. Psychopharmacology (Berl) 128:331-342.

54. Lim BK, Huang KW, Grueter BA, Rothwell PE, Malenka RC (2012) Anhedonia requires MC4R-mediated synaptic adaptations in nucleus accumbens. Nature 487:183-189.

55. Zhong P, Vickstrom CR, Liu X, Hu Y, Yu L, Yu HG, Liu QS (2018) HCN2 channels in the ventral tegmental area regulate behavioral responses to chronic stress. eLife 7:e32420.

56. Scofield MD, Heinsbroek JA, Gipson CD, Kupchik YM, Spencer S, Smith AC, Roberts-Wolfe D, Kalivas PW (2016) The nucleus accumbens: mechanisms of addiction across drug classes reflect the importance of glutamate homeostasis. Pharmacol Rev 68:816-871.

57. Tamamaki N, Tomioka R (2010) Long-range GABAergic connections distributed throughout the neocortex and their possible function. Front Neurosci 4:202.

58. Caputi A, Melzer S, Michael M, Monyer H (2013) The long and short of GABAergic neurons. Curr Opin Neurobiol 23:179-186.

59. Tritsch NX, Granger AJ, Sabatini BL (2016) Mechanisms and functions of GABA co-release. Nat Rev Neurosci 17:139-145.

60. Ramirez S, Liu X, MacDonald CJ, Moffa A, Zhou J, Redondo RL, Tonegawa S (2015) Activating positive memory engrams suppresses depression-like behaviour. Nature 522:335-339.

61. Garner AR, Rowland DC, Hwang SY, Baumgaertel K, Roth BL, Kentros C, Mayford M (2012) Generation of a synthetic memory trace. Science 335:1513-1516.

62. Tayler KK, Tanaka KZ, Reijmers LG, Wiltgen BJ (2013) Reactivation of neural ensembles during the retrieval of recent and remote memory. Curr Biol 23:99-106.

63. Huang H, Ghosh P, van den Pol AN (2006) Prefrontal cortexprojecting glutamatergic thalamic paraventricular nucleusexcited by hypocretin: a feedforward circuit that may enhance cognitive arousal. J Neurophysiol 95:1656-1668.

64. Roth MM, Dahmen JC, Muir DR, Imhof F, Martini FJ, Hofer SB (2016) Thalamic nuclei convey diverse contextual information to layer 1 of visual cortex. Nat Neurosci 19:299-307. 